\title{
Review Article \\ Religiosity and Spirituality and the Intake of Fruit, Vegetable, and Fat: A Systematic Review
}

\author{
Min-Min Tan, Carina K. Y. Chan, and Daniel D. Reidpath \\ Jeffrey Cheah School of Medicine and Health Sciences, Monash University, Sunway Campus, Jalan Lagoon Selatan, \\ 46150 Bandar Sunway Selangor Darul Ehsan, Malaysia
}

Correspondence should be addressed to Min-Min Tan; minmin.tan@gmail.com

Received 29 May 2013; Accepted 2 September 2013

Academic Editor: Arndt Büssing

Copyright (C) 2013 Min-Min Tan et al. This is an open access article distributed under the Creative Commons Attribution License, which permits unrestricted use, distribution, and reproduction in any medium, provided the original work is properly cited.

Objectives. To systematically review articles investigating the relationship between religion and spirituality (R/S) and fruit, vegetable, and fat intake. Methods. PubMed, CINAHL, and PsycInfo were searched for studies published in English prior to March 2013. The studies were divided into two categories: denominational studies and degree of R/S studies. The degree of R/S studies was further analyzed to (1) determine the categories of R/S measures and their relationship with fruit, vegetable, and fat intake, (2) evaluate the quality of the R/S measures and the research design, and (3) determine the categories of reported relationship. Results. Thirty-nine studies were identified. There were 14 denominational studies and 21 degree of R/S studies, and 4 studies were a combination of both. Only $20 \%$ of the studies reported validity and $52 \%$ reported reliability of the R/S measures used. All studies were cross-sectional, and only one attempted mediation analysis. Most studies showed a positive association with fruit and vegetable intake and a mixed association with fat intake. Conclusion. The positive association between R/S and fruit and vegetable intake may be one possible link between R/S and positive health outcome. However, the association with fat intake was mixed, and recommendations for future research are made.

\section{Introduction}

Unhealthy diet is a major risk factor in the development of noncommunicable diseases (NCD), which are responsible for about $63 \%$ of deaths globally [1]. One of the main characteristics of a healthy diet is the regular consumption of a variety of fruit and vegetable, which is associated with a lower risk of some cancers, coronary heart disease, hypertension, and stroke [2, 3]. About 1.7 million deaths worldwide are attributed to a low fruit and vegetable intake [4]. In addition, about $14 \%$ of gastrointestinal cancers, $11 \%$ of ischemic heart disease, and 9\% of stroke worldwide are also attributable to low fruit and vegetable intake [5]. Another important dietary factor related to health is fat intake. A high fat intake is associated with higher risk of coronary heart disease, diabetes, and cancers, the common NCDs [6-8].

The World Health Organization recommends a daily intake of at least $400 \mathrm{~g}$ (5 servings) of fruit and nonstarchy vegetable, and fat that is less than $30 \%$ of total dietary energy, of which less than $10 \%$ is from saturated fat and less than $1 \%$ from transfat [9]. However, due to urbanization and westernization, many countries that traditionally enjoyed high fruit and vegetable and low dietary fat consumption are moving towards a higher fat, lower fiber diet [10]. The global burden of NCD is predicted to increase further because of this global transition in lifestyles [10].

Research has shown that religion and spirituality $(\mathrm{R} / \mathrm{S})$ has a positive association with health [11]. About $80 \%$ of the studies looking at the relationship between $\mathrm{R} / \mathrm{S}$ and health examined mental health [12], showing a positive association with wellbeing, self-esteem, and optimism [13-16]; lower scores of depressive and suicidal symptoms [17, 18]; and lower stress level [19-21]. Numerous studies have also reported a positive association between $\mathrm{R} / \mathrm{S}$ and physical health, including an association with lower all-cause mortality and lower rates of diet-related diseases such as hypertension, cardiovascular diseases, and cancer [22-26].

The study of the relationship between R/S and health remains relatively novel. Initially it was not well accepted because it was thought that it is impossible (within a positivist 
framework) to study R/S scientifically. However, starting in the early 1990s, with the improvement of methodology, the study of religion and health has been increasingly recognized as a legitimate domain of scientific inquiry and is becoming more established [27]. Between 2000 and 2010, at least 21,000 quantitative studies examining the relationship between R/S and health have been published [28], covering a wide range of health outcomes and behaviors.

In the research of R/S and health, one of the major issues is defining religion and spirituality in a way that supports their measurement. Historically the notions of religion and spirituality have often been used interchangeably; however, recently there has been a trend towards distinguishing the two concepts [29]. Broadly, religion includes "beliefs, practices, and rituals related to the Transcendent or the Divine" [30], while spirituality is concerned with the "connection to that which is sacred, the transcendent" and also "a search for the transcendent and the discovery of the transcendent" [28]. Religion tends to convey a negative impression that it related to organized religion and theological rigidness, while spirituality is viewed more positively and is associated with personal experience of the transcendent. However, Koenig recommends the use of spirituality in the context of religion, that is, those who are spiritual are "deeply religious" [30].

The most commonly used R/S measure has been the single-item measuring religious attendance because of its "ease of use" [31]. In most of the studies that have used a religious attendance measure, most have also found that it is positively associated with better health outcomes [32]; for example, it has been associated with lower mortality rates $[33,34]$, better adoption of health behaviors [35, 36], more life's satisfaction [37], and a lower prevalence of hypertension [24]. However, in many studies, R/S data were collected as part of a larger study, and this can be a drawback [38, 39]. It is generally accepted that $\mathrm{R} / \mathrm{S}$ is a multidimensional construct [40], which means that a single-item measure such as religious attendance will be insufficient to capture all dimensions except possibly in the most general sense. This also limits insights that can be gained about the relationship between R/S and health. Recently, more specific scales have been developed to measure different dimensions of R/S [40].

Religion is considered important to many people around the world. One recent survey estimated that $51 \%$ of the population in the world believe in god(s) [41]. Another survey conducted in 143 countries found that the majority of people, especially those from developing countries, reported that religion was an important part of their lives [14].

One of the proposed mechanisms by which R/S benefits health is through the adoption of religious practices that are also health-promoting [42]. Many religions view the human body as sacred and include specific prohibitions against unhealthy behaviors, which are considered irreverent and not only harmful physically but also spiritually. This view, however, needs to be tempered by the fact that some religious adherence may also result in poorer health outcomes, such as extreme asceticism. Notwithstanding that, numerous studies have shown that $\mathrm{R} / \mathrm{S}$ is negatively associated with many harmful behaviors such as smoking [43, 44], alcohol drinking $[45,46]$, substance abuse $[47,48]$, and risky sexual activities
$[49,50]$ and positively associated with good health behaviors such as the use of preventive health care services [51, 52], physical activity [36], and seat belt use [53].

Certain health practices are endorsed and encouraged by most religions, such as healthy eating. In fact, most religions have specific dietary guidelines regarding what food to eat or avoid. These guidelines fall into two categories. The first category involves "a temporal abstinence from all or certain foods (fasting)" - the majority of religions have fasting guidelines, for example, Muslims fasting during Ramadan and oriental orthodox Christians fasting before Holy Communion. The second category relates to "stable and distinctive dietary habits that differ from the general population"; for example, Muslims consume halal meat and Jews consume kosher meat [54]. The main purposes of these dietary guidelines are for spiritual advancement.

$\mathrm{R} / \mathrm{S}$ might encourage the consumption of fruit and vegetable and discourage fat intake (especially animal fat) because of specific doctrines of a particular religion. For example, the teaching of Ahimsa (do no harm) in Mahayana Buddhism and Hinduism encourages their adherents to be vegetarians in order to cultivate compassion, since eating animals requires slaughtering. Nonvegetarian food is considered impure and could hinder one's spiritual development [55]. The Seventh-day Adventists are encouraged to be vegetarians, as part of a religious duty to maintain a healthy body [56]. Even in religions that do not have specific dietary guidelines or restrictions, the teaching that the body is sacred might encourage the adoption of healthier behaviors, including a healthier diet.

The long term dietary practices required by certain religions could be a protective factor in preventing dietrelated diseases. For example, the Seventh-day Adventist Church and the Church of Jesus Christ of the Latter-day Saints both encourage their believers to consume more fruit and vegetable and less fat. There is evidence from observational studies that Adventists, Mormons, and adherents of religions with strict dietary guidelines have healthier diets, better physical health, and longer lifespans than the general population $[57,58]$.

Notwithstanding the importance of food in many religions, there is a surprising scarcity of research on the relationship between R/S and diet. According to the first edition of the Handbook of Religion and Health [59], the most comprehensive review about $\mathrm{R} / \mathrm{S}$ and health to date, there were only seven studies on R/S and diet before 1990. The second edition of this Handbook (2012) reviewed 21 studies about R/S and diet between 2000 and 2012. Sixty-two percent showed a positive association; that is, a higher measured R/S is associated with a healthier diet.

A few other reviews also identified generally positive associations between R/S and a healthier diet. Groen and van der Heide [60], for instance, reviewed the role of dietary cholesterol in the development of atherosclerosis and coronary thrombosis among adherents of different religions. They found that Jews and vegetarian Trappist monks have a lower cholesterol level than the comparable groups. Shatenstein and Ghadirian [61] reviewed the differences in health behaviors, including dietary practices, among different religious groups. 
In another review, Sarri et al. [62] examined religious dietary practices and physical health among Muslims, Seventhday Adventists, orthodox Christians, Jews, Buddhists, and a few other religions. There was an inconsistent finding about the influence of Ramadan fasting on physical health among Muslims and an overall positive relationship between religious dietary practices and health in other religions.

However, to date, there has been no review that examined the relationship between $\mathrm{R} / \mathrm{S}$ and specific dietary intake. The past reviews have only examined R/S and diet in general. Thus, the purpose our review was to address this gap and systematically review the relationship between R/S and fruit, vegetable and fat intake. We hypothesized that $R / S$ was positively associated with fruit and vegetable intake, and negatively associated with fat intake.

\section{Methods}

2.1. Search Strategy. PubMed, CINAHL, and PsycInfo were searched by using two categories of key terms: religious key terms (religion, religiosity, religiousness, and spirituality) and dietary key terms (diet, food, food habits, health behavior, food preferences, eating, nutritional status, fruit, vegetable, fibers, and fats). The Boolean operator "OR" was used to combine key terms within each category, and "AND" to combine both categories. In PubMed database, the "NOT" operator was also used to eliminate studies related to clinical trials, fasting, reviews, systematic reviews, case reports, editorial, and comment. The full search strategy can be obtained from the authors.

2.2. Inclusion Criteria. To be eligible for inclusion, a paper had to fulfill the following criteria.

(1) The research analyzed the direct association between at least one quantified $\mathrm{R} / \mathrm{S}$ measure and at least one quantified measure of fruit and vegetable or fat intake. Thus, qualitative studies and case studies were excluded.

(2) The paper was published in English and in a peerreviewed journal before 1 March 2013.

\subsection{Exclusion Criteria. A paper was excluded if}

(1) R/S and fruit, vegetable, and/or fat intake were included but their relationship was not examined directly (e.g., parents' R/S and children's intake)

(2) only overall health/dietary behavior was assessed but not fruit, vegetable, and/or fat intake specifically

(3) $\mathrm{R} / \mathrm{S}$ was included as part of the measure of another variable (e.g., social support) but the direct relationship between $\mathrm{R} / \mathrm{S}$ and fruit, vegetable, and/or fat intake was not assessed;

(4) the focus of the paper was fasting and/or eating disorders;

(5) the paper examined only serum levels of nutrients and not direct intake. Serum level or biomarkers of nutrients might not be an accurate indicator of fruit, vegetable, and fat intake since the nutrients could be obtained from supplements;

(6) the paper examined fiber intake but did not specify its dietary source as fruit and vegetable. Fiber could be obtained from supplements and nonfruit or vegetable food source such as grains.

The references and bibliographies of the papers were also examined to identify other relevant articles. Previous reviews of the relationship between diet (generally) and R/S were also examined $[28,59,61,62]$, and in one case the review author was contacted for his list of papers, which were not detailed in the review itself.

\section{Analysis}

The frequency and types of fruit, vegetable, and fat intake measures used were first examined. The measures were categorized into dietary records, 24-hour dietary recall, food frequency, brief dietary assessment methods, and dietary history. A dietary record is a detailed record of all food and drinks consumed over a period of time by a respondent; in 24-hour dietary recall, a respondent is asked about the food and drinks he/she consumed during the past 24 hours; a food frequency questionnaire is a list of commonly consumed food that could be selected by respondents; brief dietary assessments are used to estimate the intake of a nutrient or a type of food but do not assess overall diet; dietary history assesses dietary patterns over time [63].

The studies were divided into two categories: (1) denominational studies that compared fruit, vegetable, and/or fat intake between members of different religions, or denominations within the same religion, or between a religion with the general population and (2) degree of R/S studies that examined the degree of $\mathrm{R} / \mathrm{S}$ and its association with fruit and vegetable and/or fat intake. The two categories were analyzed separately.

The analyses of degree of $R / S$ studies were guided by Rew and Wong [64] and Wong et al. [65]. First the categories of R/S measures were analyzed. The classification scheme was based on Wong et al. [65], which is a modification of Hackney and Sanders [66]. There are six categories: institutional (social and behavior aspects of R/S e.g., attendance and social support), ideological (R/S beliefs e.g., importance of religion), personal devotion (personal and internalized devotion, e.g., private prayer), existential (measures that are spiritual but not religious, e.g., spiritual wellbeing), multidimensional (examined more than one category of $\mathrm{R} / \mathrm{S}$ ), and generic (e.g., one-item measure that asks about how religious are the respondents) [65]. The relationships (positive (+), negative (-), mixed, or none) between $\mathrm{R} / \mathrm{S}$ measures and fruit, vegetable, and fat intake were identified.

The quality of R/S measures was assessed by examining whether their validity and reliability were reported. The number of studies that used single-item measure was also examined. Many R/S and health studies relied solely on the use of single-item measure of religious attendance, which has its limitations in health research [38]. The quality of research 


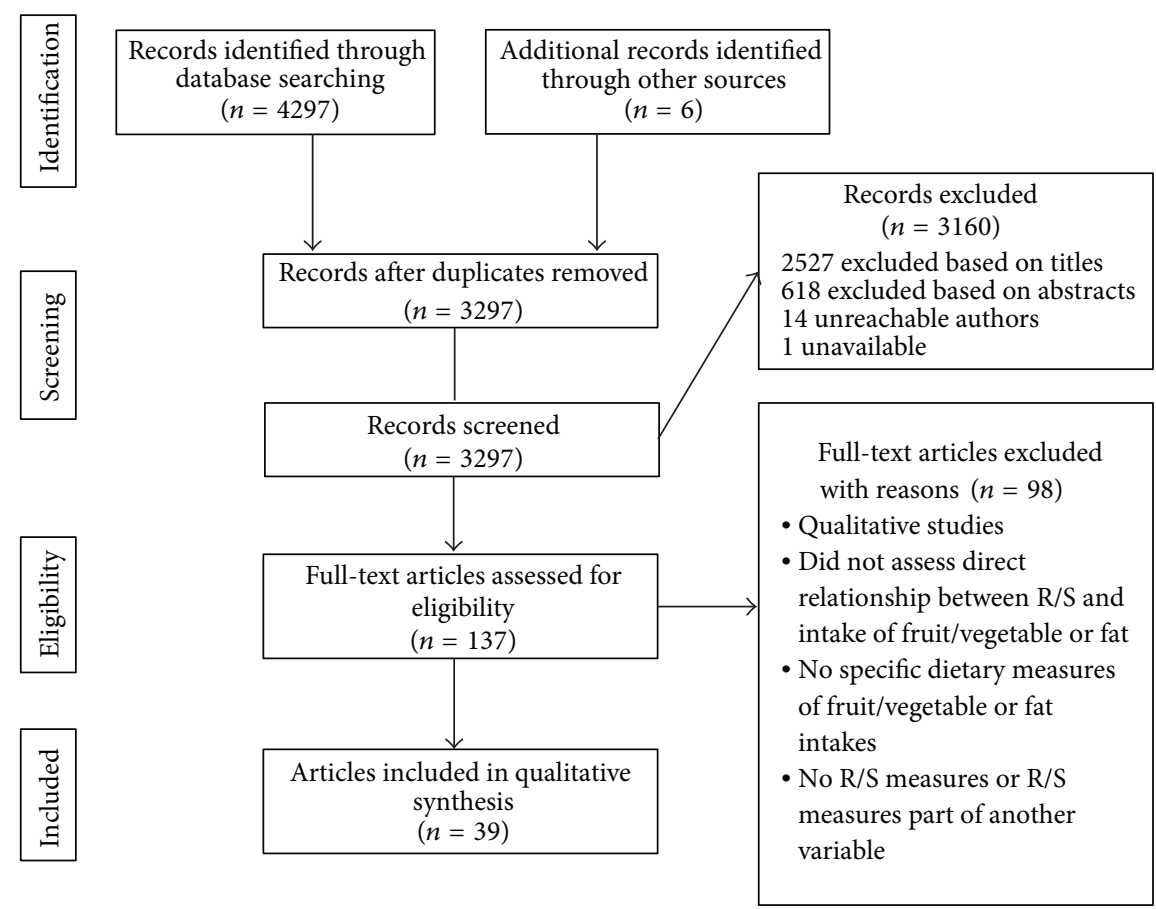

Figure 1: Articles selection process.

design (control for covariates, utilization of longitudinal data, and investigation of mediators) was assessed [64]. The studies were also categorized based on their reported relationship between R/S and fruit, vegetable, and fat intake.

\section{Results}

Out of the 3298 potentially relevant papers identified by the database search strategy, 32 papers fulfilled the inclusion criteria. An additional seven papers were obtained through cross reference of included papers and previous reviews. Figure 1 shows the flowchart of article selection process. All of the 39 studies were cross-sectional. There are 14 denominational studies that do not contain other R/S measures, 21 studies that examined only degree of R/S, and four that included both denominational differences and degree of R/S. See Table 1 for the table of characteristics of the 39 studies.

The majority $(77 \%)$ of the studies were conducted in the United States. Five were conducted in other Western countries (two in Australia (5.1\%), and one each $(2.6 \%)$ in Scotland, Slovakia, and Canada), two in Israel (5.1\%) one in Japan $(2.6 \%)$, and one in South Korea (2.6\%). Four studies included only female samples. Eleven studies were racespecific; seven examined African Americans, two examined non-Hispanic Whites, one examined Koreans, and one examined Japanese. Thirty-two of the studies (79.4\%) included samples that were predominantly Christians. Four studies examined Jews and three examined Buddhists.

4.1. Assessment of Dietary Intake. Out of the 39 studies, 12 examined fruit, vegetable, and fat intake, 14 examined only fruit and vegetable intake, and the other 13 only examined fat intake.

Table 3 shows the categories of dietary assessments of fruit, vegetable, and fat intake. Among the five categories of dietary assessment methods, brief dietary assessments were the most used, followed by food frequency. The most used brief dietary assessment was the Fat- and Fiber-Related Behavior Questionnaire [67], which was included in four studies, followed by the National Institute's 5-A-Day Survey [68], which was included in three studies. Three studies used more than one dietary assessment method, and two used more than one brief dietary assessment.

4.2. Denominational Studies. A total of 18 studies were analyzed. Eight (44\%) of them compared Seventh-Day Adventists with the other denominations (Catholics, Methodists, and Mormons) or non-Adventists, three compared fruit, vegetable, and fat intake, three compared only fruit and vegetable intake, and two compared only fat intake. Among the six studies that compared fruit and vegetable intake, three (50\%) showed that Adventists consumed significantly more fruit and vegetable than members of other denominations and non-Adventists, one (16.7\%) had positive but nonsignificant association, one was nonsignificant in vegetable intake but significant in higher fruit intake, and one showed that Adventists consumed less deep fried vegetable.

Five studies compared total fat intake between Adventists and non-Adventists. Two (40\%) showed that Adventists consumed less fat. One showed that Adventists consumed less fat when comparing total fat in grams, but similar amount of fat as non-Adventists when comparing the percentage of energy from fat. Another study showed that Adventist 


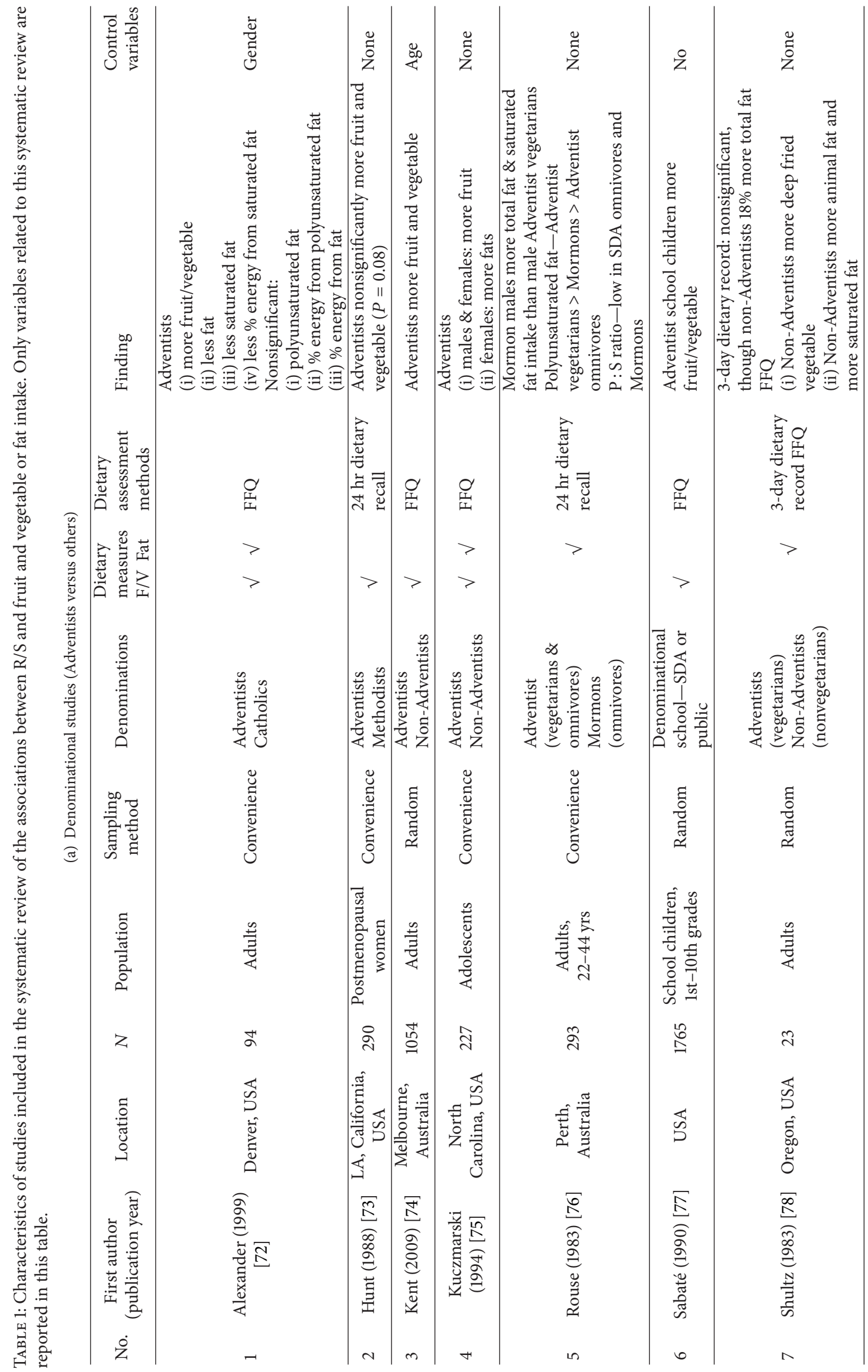




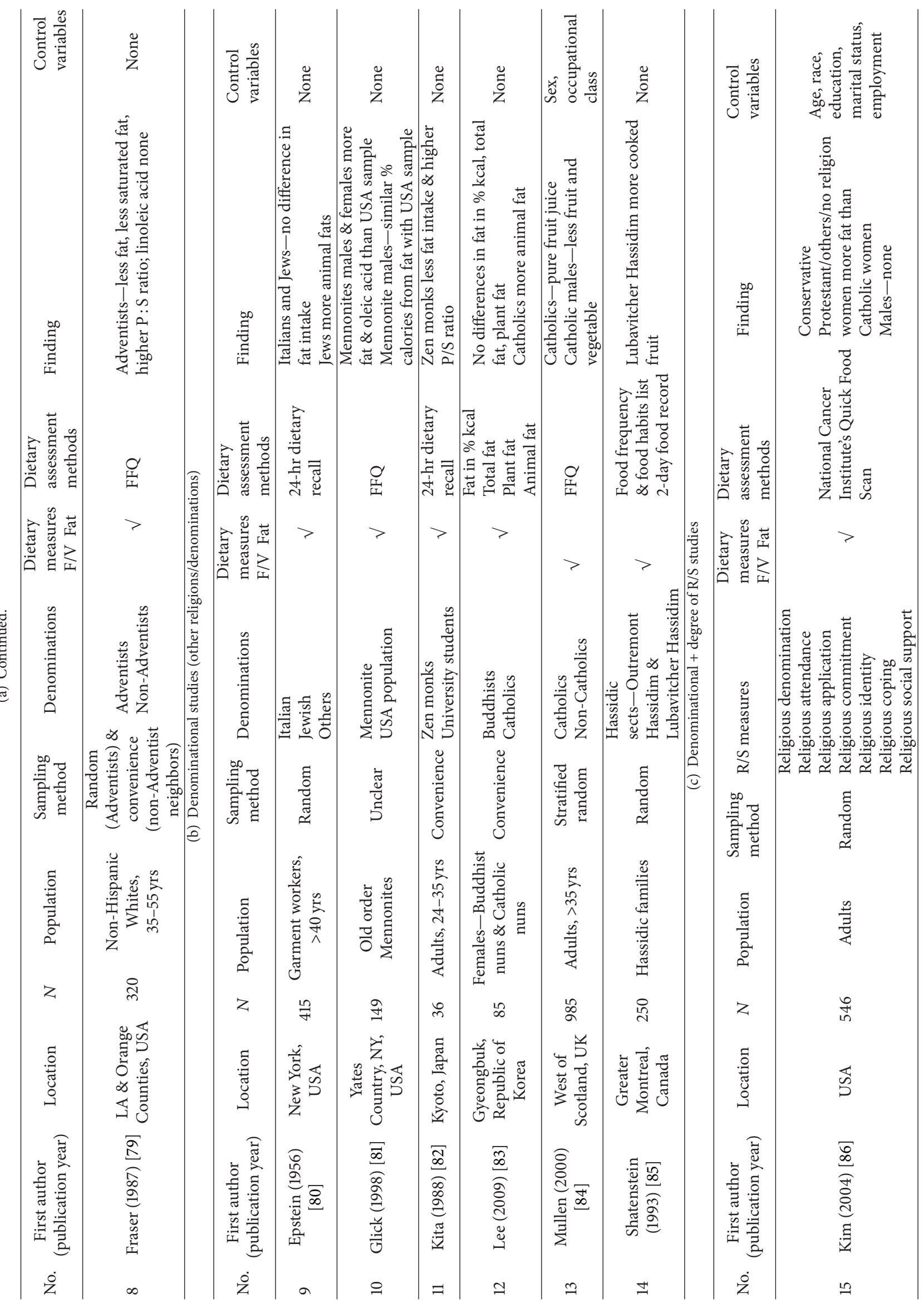




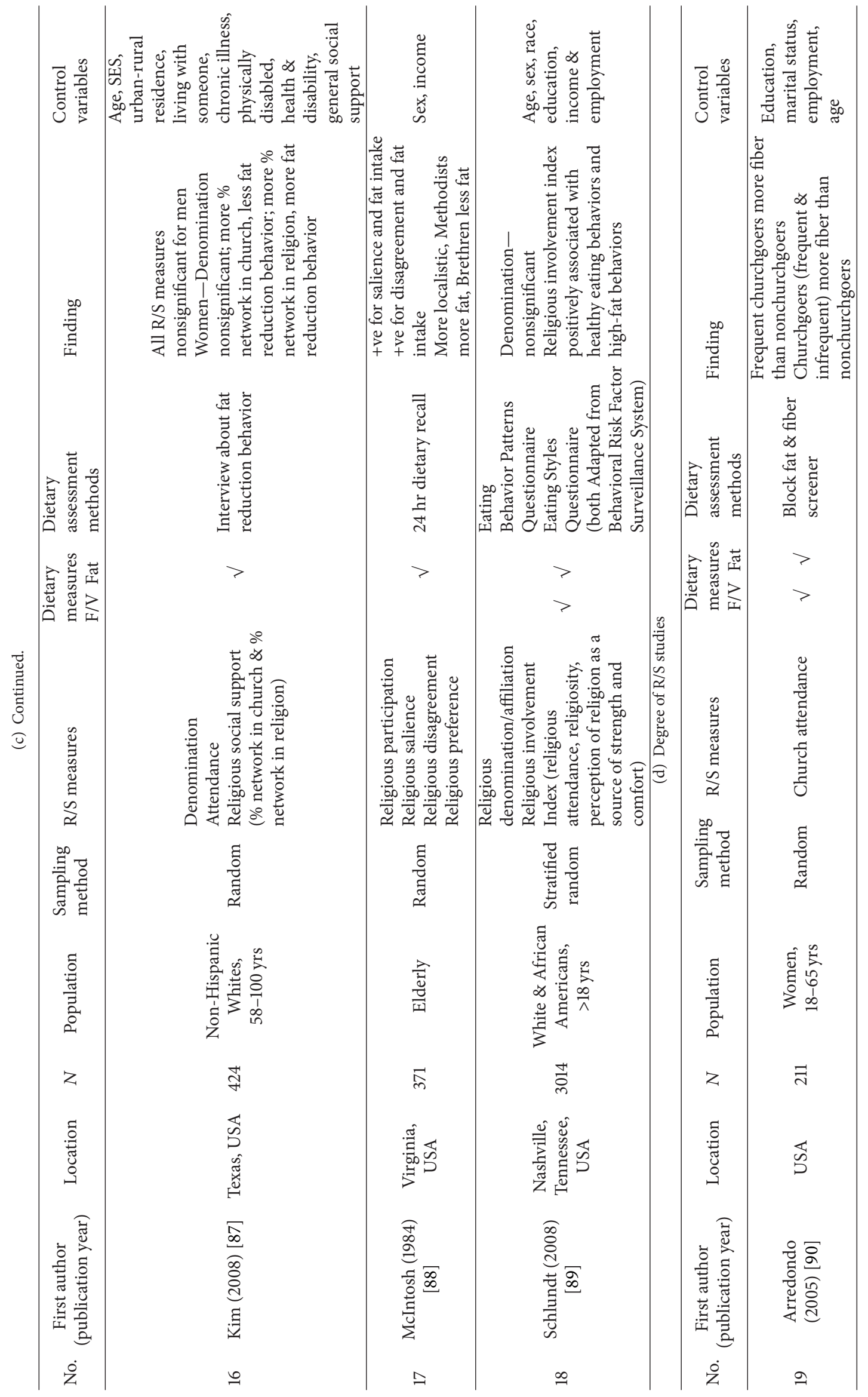




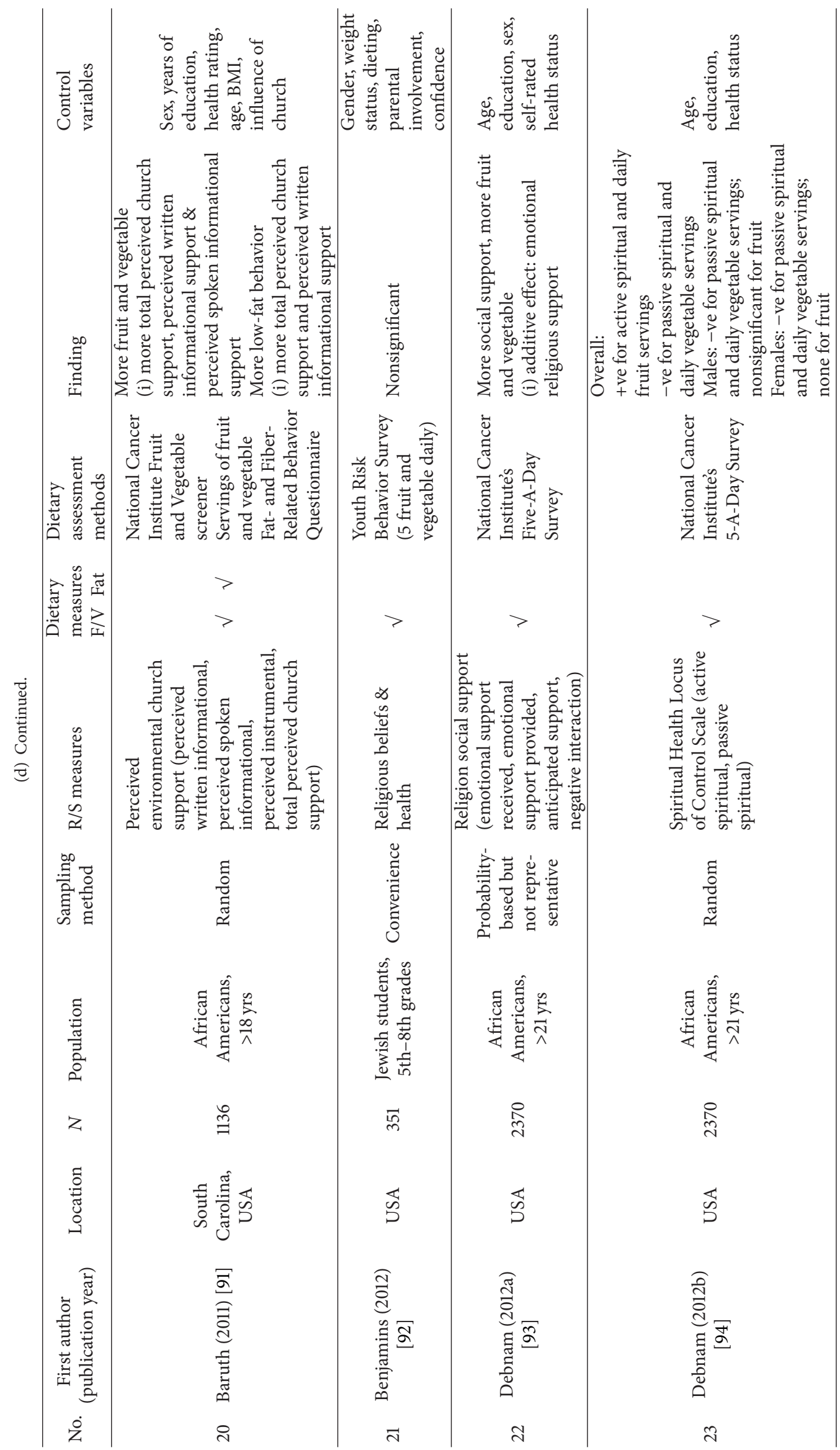




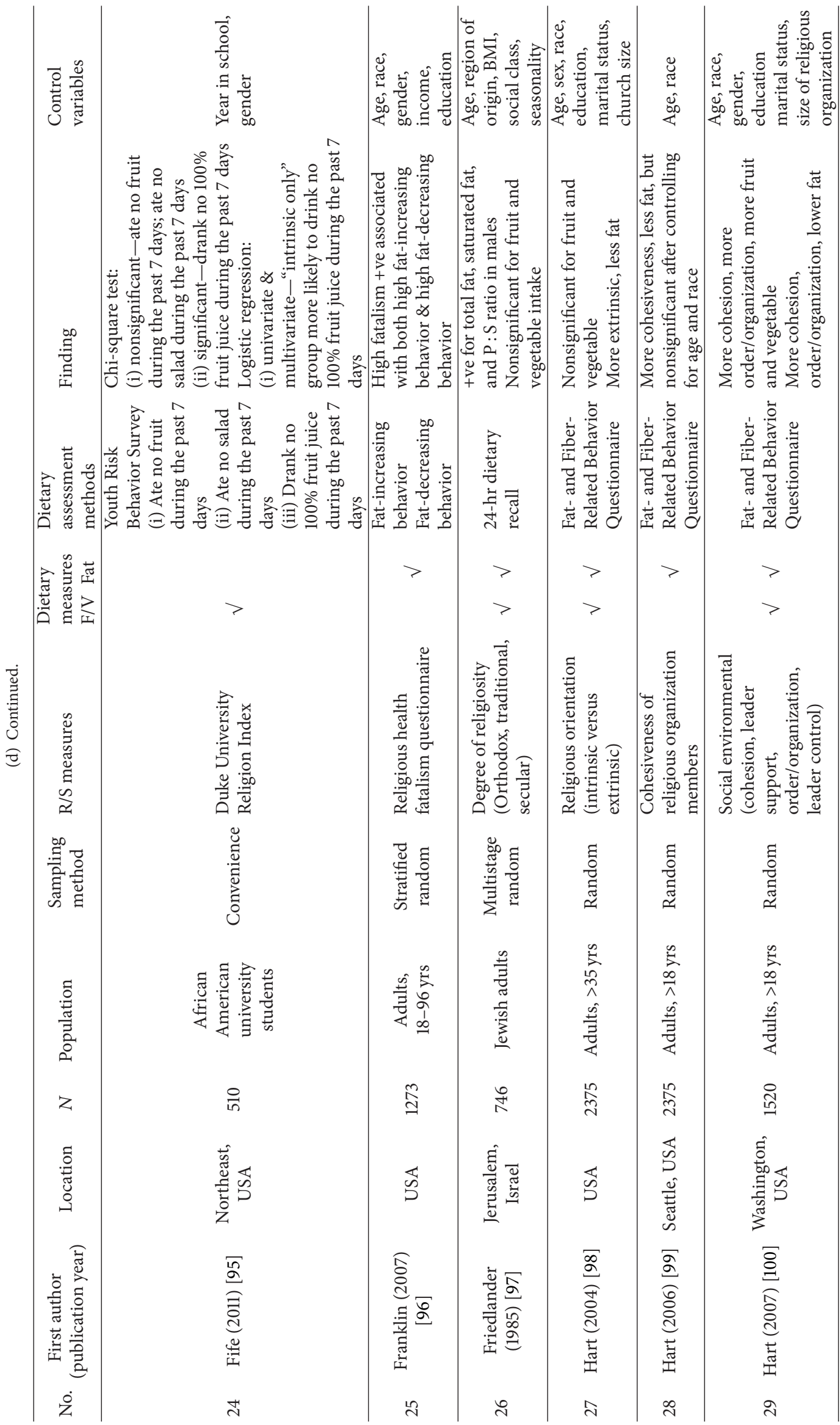




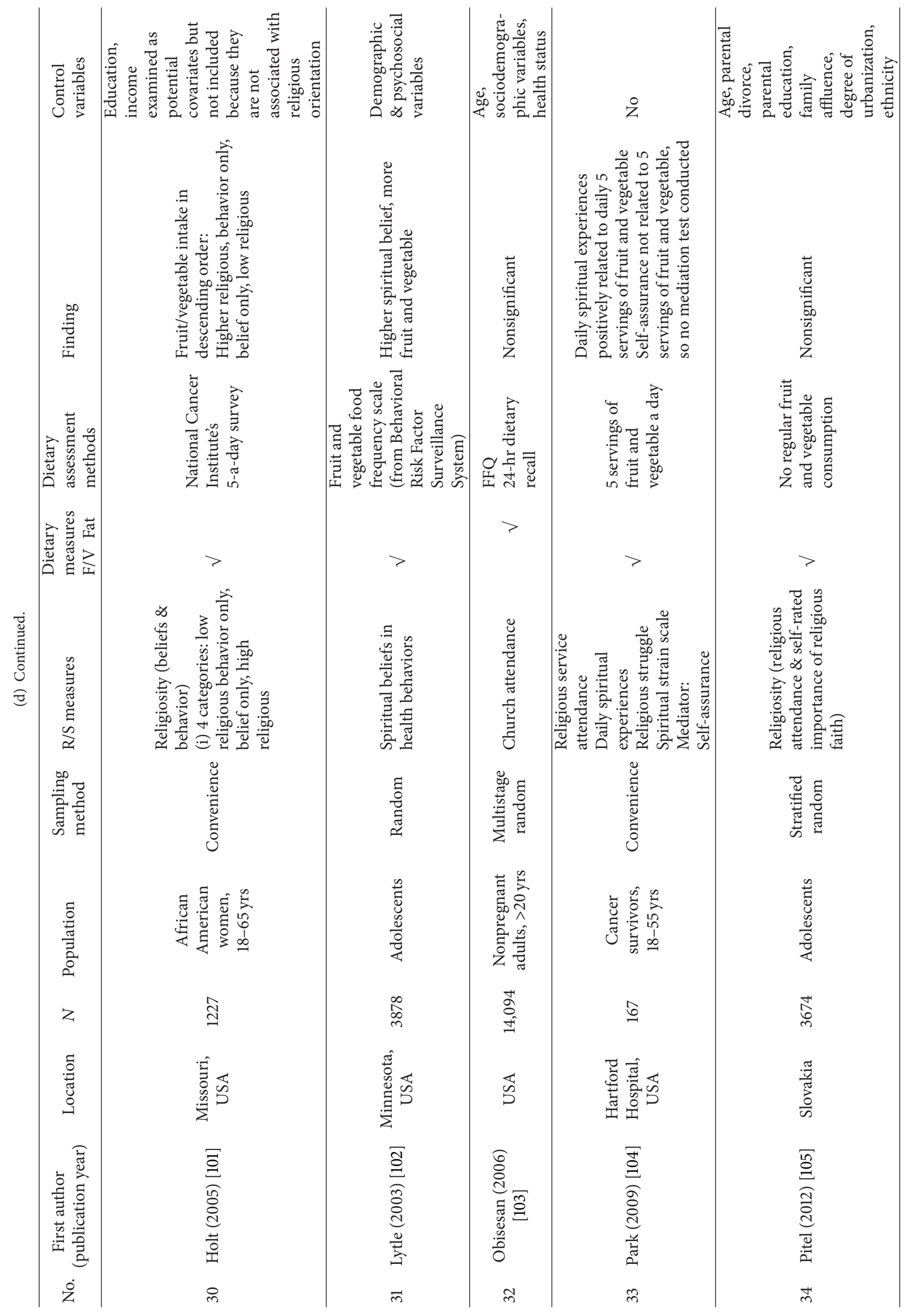




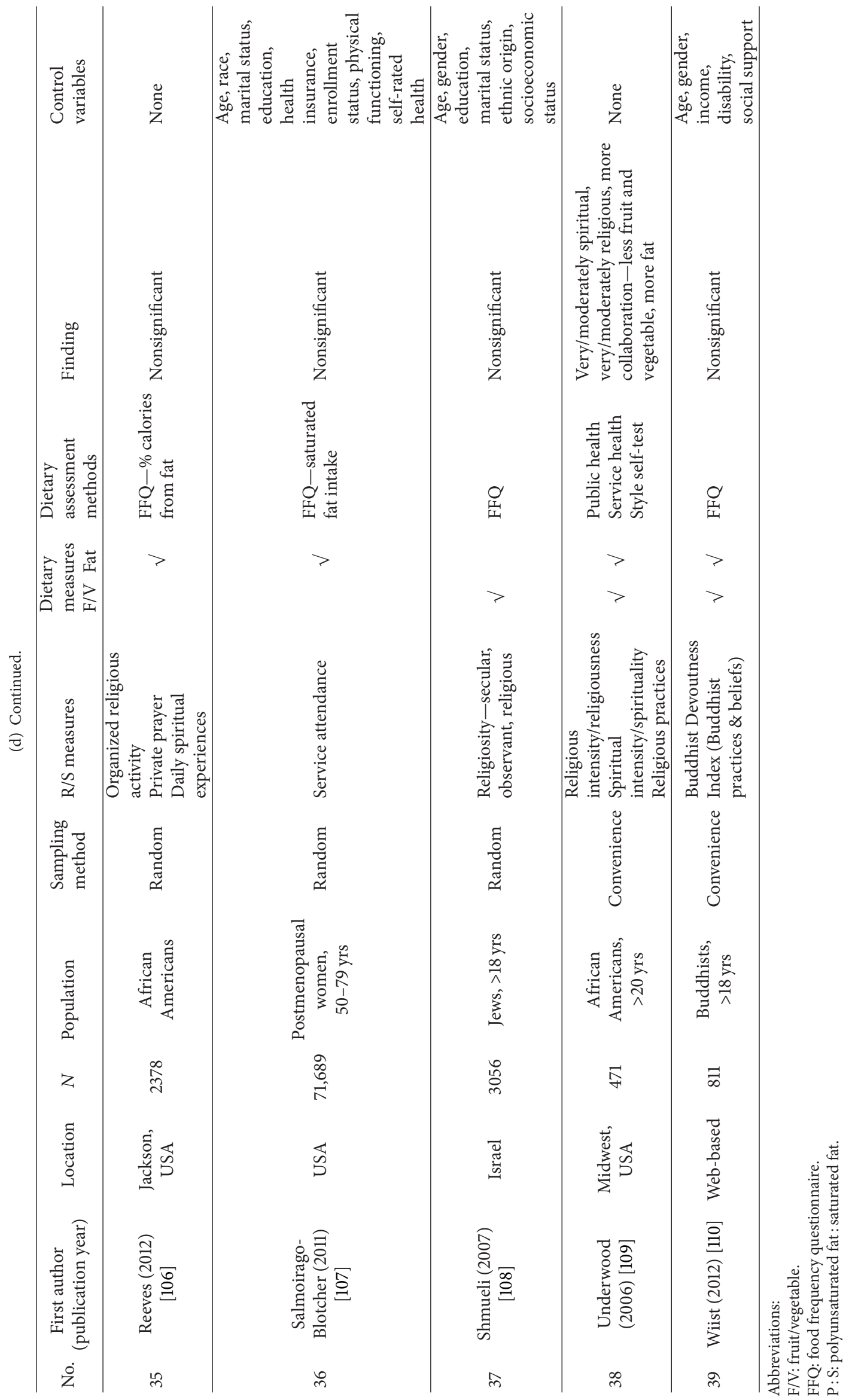


females consumed more fat. One showed no significant relationship. These five studies also examined the intake of saturated fat, and all found that Adventists consumed less saturated fat, even though their total fat intake was similar to those of non-Adventists. Three of the studies also compared the intake of unsaturated fat. Two found no significant relationship, and one found that among Adventists, the vegetarians consumed more unsaturated fat than Mormons, but Adventist omnivores consumed less saturated fat than the Mormons. Among the studies that compared unsaturated fat intake, two also looked at the polyunsaturated fat and saturated fat $(\mathrm{P}: \mathrm{S})$ ratio and found that Adventists had a higher $\mathrm{P}: \mathrm{S}$ ratio.

Two of the denominational studies examined Jews. One compared the Jews with the general population in Italy and found that there was no difference in fat intake between the two groups. However, Jews consumed more animal fat than the general population. Another study compared two Jewish Hassidic sects and found that Lubavitcher Hassidim consumed more cooked fruit.

There are two denominational studies that examined fat intake in Buddhists. The study that compared Japanese Zen Buddhist monks with the general population in Japan found that Zen Monks consumed less total fat and saturated fat, more unsaturated fat, and had a higher P:S ratio. However, another study that compared Buddhist nuns with Catholic nuns found no significant difference in total fat and unsaturated fat intake, but Catholic nuns consumed more animal fat.

One study compared Mennonites with the general US population and found that the Mennonites have higher total fat, saturated fat, and unsaturated fat intake. Another one study compared Catholics with non-Catholics in Scotland and found that Catholics consumed less pure fruit juice and Catholic males consumed less fruit and vegetable.

Four studies were multidenominational. One examined fruit, vegetable, and fat intake and found no significant relationship. Three studies examined fat intake only. One found no significant association. One study found that religious denomination mediates fat intake. One showed that among females, conservative protestant and those who have no religious preferences consumed more fat than Catholics.

4.3. Degree of Religiosity Studies. A total of 25 studies were analyzed. The $\mathrm{R} / \mathrm{S}$ measures were categorized into the six categories described in the previous section.

Table 4 shows the categories of R/S measures and their association with fruit and vegetable intake. The most commonly used R/S measures are multidimensional (36.8\%). Among the $19 \mathrm{R} / \mathrm{S}$ measures, eight (42.1\%) showed a positive association with fruit and vegetable intake and another seven (36.8\%) showed no significant relationship. Among the seven measures that showed no significant relationship, four of them showed evidence of a positive trend in the relationship between fruit and/or vegetable intake.

Table 5 shows the categories of R/S measures and their association with total fat intake. The most commonly used $\mathrm{R} / \mathrm{S}$ measures are institutional (40.7\%). Among the $27 \mathrm{R} / \mathrm{S}$ measures, 15 (55.6\%) showed no significant relationship between R/S and total fat intake, while seven (25.9\%) showed a negative relationship. Among studies that show no significant relationship, five showed evidence of a positive trend, and seven showed evidence of a negative trend.

In addition to total fat intake, three studies also examined saturated fat intake. Two studies showed no significant association. One examined the degree of orthodoxy among Jews and found that more Orthodox Jews consumed less total fat and saturated fat, more unsaturated fat, and have a higher $\mathrm{P}: \mathrm{S}$ ratio.

Only 20\% (5 out of 25) of the papers reported the validity of R/S measures, and 52\% (13 out of 25) reported reliability of at least one of the R/S measures. Of the 12 studies that do not report reliability, three of them utilized a singleitem measure of attendance. The majority of the studies (88\%) controlled for covariates such as age, gender and years of education. All the studies were cross-sectional. Only one study investigated the mediator between R/S measures and healthy behaviors. However, since the mediator (selfassurance) was not associated with the intake of fruit and vegetable in the study, no further mediation test was carried out.

Table 6 shows the number of studies categorized based on their reported relationship. Of the 17 studies that examined the degree of R/S and fruit and vegetable intake, $\mathrm{R} / \mathrm{S}$ reported positive association with fruit and vegetable intake in about half $(52.9 \%)$ of the studies and no association in $35.3 \%$ of the studies. As for fat intake, almost half (46.7\%) of the studies reported no association, and an equal number (20\%) reported positive and negative findings.

\section{Discussion}

About half of the denominational studies compared Adventists and non-Adventists. Healthy eating is one of the major teachings in the Adventist Church; other Christian denominations (except the Church of Jesus Christ of the Latterday Saints) do not emphasize healthy eating as much as the Adventist Church. Thus, it is not surprising to find that Adventists generally consumed more fruit and vegetable and less total fat and saturated fat than non-Adventists. Similarly in studies that compared Buddhist monks and nuns with non-Buddhists, because of the teaching of Ahimsa (do no harm), Buddhists monks and nuns are vegans, and again it is not surprising to find that they consumed less saturated fat or animal fat. A weakness of denominational studies is the assumption of homogeneity of dietary practices among the members within a denomination. Denominational studies only compared denominational differences as a whole and omitted the individual variation of $\mathrm{R} / \mathrm{S}$ of members within a denomination. It is unknown whether this variation is associated with dietary intake. In addition, denominational studies are "likely to be confounded with region and the effects of socioeconomic status" [69], and almost all of the denominational studies in this review did not control for covariates.

Four of the denominational studies included samples from various Christian denominations. Three of the studies found no significant relationship between religious denomination and dietary intake. The nonsignificant findings were 
TABLE 2

\begin{tabular}{|c|c|}
\hline Categories of $\mathrm{R} / \mathrm{S}$ measures & $\begin{array}{c}\text { Paper no. in } \\
\text { Table } 1 \\
\end{array}$ \\
\hline \multicolumn{2}{|l|}{ Institutional } \\
\hline Attendance & $\begin{array}{c}15,16,19,32 \\
33,36\end{array}$ \\
\hline Organized religious activity & 35 \\
\hline Perceived environmental church support & 20 \\
\hline Religious social support & $15,16,22$ \\
\hline Cohesiveness of religious organization members & 28 \\
\hline Social environment & 29 \\
\hline Religious identity & 15 \\
\hline \multicolumn{2}{|l|}{ Ideological } \\
\hline Religious beliefs and health & 21 \\
\hline Religious application & 15 \\
\hline Religious coping & 15 \\
\hline Spiritual belief in health behaviors & 31 \\
\hline Religious salience & 17 \\
\hline Religious disagreement & 17 \\
\hline Religious problem-solving & 38 \\
\hline Religious struggle & 33 \\
\hline Spiritual health locus of control & 23 \\
\hline Religious health fatalism & 25 \\
\hline \multicolumn{2}{|l|}{ Private devotion } \\
\hline Private prayer & 35 \\
\hline Religious orientation (intrinsic versus extrinsic) & 27 \\
\hline \multicolumn{2}{|l|}{ Spiritual } \\
\hline Daily spiritual experience & 33,35 \\
\hline \multicolumn{2}{|l|}{ Multidimensional } \\
\hline DUREL & 24 \\
\hline Religiosity (beliefs and practices) & 30 \\
\hline Religious participation & 17 \\
\hline Religiosity (attendance and self-rated importance) & 34 \\
\hline Religious involvement index & 18 \\
\hline Jewish religiosity & 26,37 \\
\hline Religious commitment & 15 \\
\hline Buddhist devoutness index & 39 \\
\hline \multicolumn{2}{|l|}{ Generic } \\
\hline Religious intensity & 38 \\
\hline Spiritual intensity & 38 \\
\hline
\end{tabular}

probably due to the fact that respondents from various denominations interpreted questionnaire items related to R/S differently.

Although a meta-analysis was not conducted due to heterogeneity of R/S measures and dietary measures, the present review on the relationship between degree of $\mathrm{R} / \mathrm{S}$ and fruit and vegetable intake points towards a positive association; that is, a higher score of $\mathrm{R} / \mathrm{S}$ is associated with higher fruit and vegetable intake. About half of the Christian studies showed a significant positive relationship with fruit and vegetable. This is consistent with the previous review that $\mathrm{R} / \mathrm{S}$ is associated with a better diet [28]. The results of the present review also suggest that the regular consumption of fruit and vegetable may be one of the possible links between R/S and positive health outcomes. Other possible links include adoption of other health behaviors such as the no smoking and drinking; better social integration and social support from religious communities; higher self-esteem and personal efficacy among the more religious; better coping resources and behaviors; positive emotions from religious practice; and healthy beliefs [42].

Six of the 17 studies reported no association between degree of R/S and fruit and vegetable intake. All three studies that included only Jewish samples showed no association. This may arise because the dietary restrictions of Judaism only revolve around meat and animal products and not on fruit and vegetable. The consumption of fruit and vegetable is neither restricted nor encouraged.

The findings for fat intake contradicted the previous review. Almost half of the studies reported no association, and an equal number reported positive and negative findings. The contradiction might be due to the fact that the previous review examined diet as a whole and not particularly fat intake. There are other studies which showed that R/S was positively associated with greater body weight [70] and obesity [71], both of which might be related to high fat intake. The proposed explanation of higher prevalence of obesity among religious people could be that religious community is more accepting towards obese people, rather than R/S itself being the cause of obesity [71]. Kim et al. [70] found that the positive relationship between $\mathrm{R} / \mathrm{S}$ and greater body weight disappeared after controlling for health behaviors, particularly smoking. None of the degree of R/S studies in this review controlled for health behaviors and it is unknown whether similar attenuation effect was also found between $\mathrm{R} / \mathrm{S}$ and fat intake.

Most of the studies in this systematic review included samples that were from the USA and Western countries where Christianity is the predominant religion; only two studies were conducted in Asia and one in Africa, even though religion is considered important by most people on these two continents [14]. None of the studies examined Hinduism and Islam, the two major religions in the world besides Christianity. Only three studies examined Buddhists; however, they were Buddhists in the USA rather than in Asia, even though there is a higher percentage of Buddhists in Asia.

The most frequently used dietary assessment methods were brief dietary assessments. However, they are crude estimates of dietary intake. For example, the Fat- and FiberRelated Behavior Questionnaire does not report dietary intake per se but only an overall score of fruit and vegetable and fat intake. Dietary records are considered the "gold standard" of dietary assessment methods [68]. However, only two studies in this review utilized dietary records. No studies used dietary history, probably because they are crosssectional and assessing dietary history is time-consuming.

The present review also showed a diversity of R/S measures used. Even within a category (see Table 2), there was variation. For example, the R/S measures coded as "institutional," defined as "measures that focused on the social and behavioral aspects of R/S" [65], included attendance and 
TABLE 3: Dietary assessments of fruit and vegetable and fat intake.

\begin{tabular}{lcccc}
\hline \multirow{2}{*}{ Dietary assessment methods } & \multicolumn{2}{c}{ Fruit and vegetable } & \multicolumn{2}{c}{ Fat } \\
& Total & $\%$ & Total & $\%$ \\
\hline Dietary records & 0 & 0 & 2 & 7.4 \\
24-hour dietary recall & 2 & 6.9 & 6 & 22.2 \\
Food frequency & 8 & 27.6 & 9 & 33.3 \\
Brief dietary assessments & 19 & 65.5 & 10 & 37.0 \\
Dietary history & 0 & 0 & 0 & 0 \\
\hline Total & 29 & 100.0 & 27 & 100.0 \\
\hline
\end{tabular}

TABLE 4: Categories of R/S measures and fruit and vegetable intake.

\begin{tabular}{|c|c|c|c|c|c|c|}
\hline \multirow{2}{*}{ Categories } & \multicolumn{4}{|c|}{ Relationships } & \multirow{2}{*}{ Total } & \multirow{2}{*}{$\%$} \\
\hline & + & - & Mixed & None & & \\
\hline Institutional & 4 & 0 & 0 & 1 & 5 & 26.3 \\
\hline Ideological & 1 & 1 & 1 & 1 & 4 & 21.1 \\
\hline Personal devotion & 0 & 0 & 0 & 0 & 0 & 0.0 \\
\hline Existential & 1 & 0 & 0 & 0 & 1 & 5.3 \\
\hline Multidimensional & 2 & 0 & 1 & 4 & 7 & 36.8 \\
\hline Generic & 0 & 0 & 1 & 1 & 2 & 10.5 \\
\hline Total & 8 & 1 & 3 & 7 & 19 & 100 \\
\hline
\end{tabular}

Mixed: when an R/S measure is positively associated with fruit intake and negatively associated with vegetable intake or vice versa, or when a $\mathrm{R} / \mathrm{S}$ measure is positively/negatively associated with fruit intake and not associated with vegetable intake or vice versa.

TABLE 5: Categories of R/S measures and total fat intake.

\begin{tabular}{|c|c|c|c|c|c|c|}
\hline \multirow{2}{*}{ Categories } & \multicolumn{4}{|c|}{ Relationships } & \multirow{2}{*}{ Total } & \multirow{2}{*}{$\%$} \\
\hline & + & - & Mixed & None & & \\
\hline Institutional & 2 & 0 & 1 & 8 & 11 & 40.7 \\
\hline Ideological & 0 & 3 & 1 & 2 & 6 & 22.2 \\
\hline Personal devotion & 1 & 0 & 0 & 1 & 2 & 7.4 \\
\hline Existential & 0 & 0 & 0 & 1 & 1 & 3.7 \\
\hline Multidimensional & 0 & 2 & 0 & 3 & 5 & 18.5 \\
\hline Generic & 0 & 2 & 0 & 0 & 2 & 7.4 \\
\hline Total & 3 & 7 & 2 & 15 & 27 & 100 \\
\hline
\end{tabular}

Positive (+) relationship: a higher score of R/S measure is associated with lower fat intake; negative relationship (-): a higher score of R/S measure is associated with higher fat intake.

Mixed: when an R/S measure is both positively and negatively associated to fat intake.

TABLE 6: Categories of studies.

\begin{tabular}{lccccc}
\hline \multirow{2}{*}{ Dietary intake } & \multicolumn{5}{c}{ Relationships } \\
& + & - & Mixed & 0 & Total \\
\hline Fruit and vegetable & 9 & 1 & 1 & 6 & 17 \\
Fat & $3^{*}$ & $3^{*}$ & 2 & 7 & 15 \\
\hline
\end{tabular}

Notes: ${ }^{*}$ positive (+): a higher score of R/S measure is associated with lower fat intake; negative (-): a higher score of R/S measure is associated with higher fat intake.

religious social support, which are two different concepts that warrant further categorization.
Because of the diversity of $R / S$ measures and that different $\mathrm{R} / \mathrm{S}$ measures show different effects in different populations, it was proposed that $\mathrm{R} / \mathrm{S}$ should be treated as a multidimensional construct [69]. However, less than a third of the R/S measures included in the present review are multidimensional.

Very little information was provided with regard to the psychometric properties of the R/S measures. In this review, only $20 \%$ of the papers reported validity and $52 \%$ reported reliability of at least one R/S measure. However, only three studies (out of 25) used single-item measures of religious attendance. The overall quality of the degree of R/S studies was mixed, most of the studies control for covariates, but none of them used longitudinal data and only one attempted mediation analysis. All the studies were cross-sectional; thus the inference of causal relationship between R/S and fruit, vegetable, and fat intake could not be established. In $\mathrm{R} / \mathrm{S}$ and health research, there are very few experimental studies, and the wide use of cross-sectional data is another major drawback, in addition to lack of clear definition of R/S [39].

There are several limitations in this review. Only peerreviewed studies that are published in English were included. This could be the reason why most studies in this review were from Western countries and included mostly Christian samples. Second, unpublished studies were excluded and this might lead to publication bias, since studies with significant results are more likely to be published. Nonetheless, the present review was the first that examined the relationship of $\mathrm{R} / \mathrm{S}$ with specific dietary intake.

The contradictory findings among the studies of degree of R/S point to the need for more studies that control for health behaviors, for example, smoking, and use more rigorous dietary assessment method. In addition, more studies are needed that include participants of other religions, especially those of Eastern traditions and from non-Western countries. There is also a need to use more rigorous R/S measures that are validated, reliable, and multidimensional.

\section{Conclusion}

Overall, the denominational studies showed that religious denomination is significantly related to fruit, vegetable, and fat intake. Specifically, the Adventists consumed more fruit and vegetable and less fat than non-Adventists. However, the relationship between the degree of $\mathrm{R} / \mathrm{S}$ and dietary intake is mixed. The results of this review suggest that future research on R/S and diet may help explain the possible mechanism between religion and health. Methodology more sophisticated than observational studies is required. Longitudinal study methodologies (while still often observational) may enhance our understanding of underlying mechanisms. As religion is important for many people and affects their diet, improved methodological quality of $\mathrm{R} / \mathrm{S}$ and diet research will surely shed more light on this area.

\section{References}

[1] World Health Organization, Global Status Report on Noncommunicable Diseases 2010, World Health Organization, 2011. 
[2] The American Institute for Cancer Research, Food, Nutrition, Physical Activity, and the Prevention of Cancer: A Global Perspective, The American Institute for Cancer Research, 2007.

[3] M. A. S. Van Duyn and E. Pivonka, "Overview of the health benefits of fruit and vegetable consumption for the dietetics professional: selected literature," Journal of the American Dietetic Association, vol. 100, no. 12, pp. 1511-1521, 2000.

[4] World Health Organization, World Health Report 2002: World Health Report: Reducing Risks to Health Noncommunicable Diseases, World Health Organization, 2002.

[5] World Health Organization, Global Health Risks: Mortality and Burden of Disease Attributable to Selected Major Risks, World Health Organization, 2009.

[6] E. Cho, D. Spiegelman, D. J. Hunter et al., "Premenopausal fat intake and risk of breast cancer," Journal of the National Cancer Institute, vol. 95, no. 14, pp. 1079-1085, 2003.

[7] K. Oh, F. B. Hu, J. E. Manson, M. J. Stampfer, and W. C. Willett, "Dietary fat intake and risk of coronary heart disease in women: 20 years of follow-up of the nurses' health study," The American Journal of Epidemiology, vol. 161, no. 7, pp. 672-679, 2005.

[8] J. A. Marshall, R. F. Hamman, and J. Baxter, "High-fat, lowcarbohydrate diet and the etiology of non-insulin-dependent diabetes mellitus: the San Luis Valley Diabetes Study," The American Journal of Epidemiology, vol. 134, no. 6, pp. 590-603, 1991.

[9] World Health Organization, "Diet, nutrition and the prevention of chronic diseases: report of a joint WHO/FAO expert consultation," in WHO Technical Report Series, 2003.

[10] B. M. Popkin, "The nutrition transition and obesity in the developing world," Journal of Nutrition, vol. 131, no. 3, pp. 871S873S, 2001.

[11] L. M. Chatters, "Religion and health: public health research and practice," Annual Review of Public Health, vol. 21, pp. 335-367, 2000.

[12] H. G. Koenig, "Religion, spirituality, and health: the research and clinical implications," ISRN Psychiatry, vol. 2012, Article ID 278730, 33 pages, 2012.

[13] L. B. Koenig and G. E. Vaillant, "A prospective study of church attendance and health over the lifespan," Health Psychology, vol. 28, no. 1, pp. 117-124, 2009.

[14] S. Crabtree and B. Pelham, Religion Provides Emotional Boost To World's Poor, 2009.

[15] N. Krause, "Religious meaning and subjective well-being in late life," Journals of Gerontology A, vol. 58, no. 3, pp. S160-S170, 2003.

[16] N. Krause, "Religious doubt and psychological well-being: a longitudinal investigation," Review of Religious Research, vol. 47, no. 3, pp. 287-302, 2006.

[17] B. W. Van Voorhees, D. Paunesku, S. A. Kuwabara et al., "Protective and vulnerability factors predicting new-onset depressive episode in a representative of U.S. adolescents," Journal of Adolescent Health, vol. 42, no. 6, pp. 605-616, 2008.

[18] P. A. Nisbet, P. R. Duberstein, Y. Conwell, and L. Seidlitz, "The effect of participation in religious activities on suicide versus natural death in adults 50 and older," Journal of Nervous and Mental Disease, vol. 188, no. 8, pp. 543-546, 2000.

[19] R. W. Larson, D. M. Hansen, and G. Moneta, "Differing profiles of developmental experiences across types of organized youth activities," Developmental Psychology, vol. 42, no. 5, pp. 849-863, 2006.
[20] D. Oman, J. Hedberg, and C. E. Thoresen, "Passage meditation reduces perceived stress in health professionals: a randomized, controlled trial," Journal of Consulting and Clinical Psychology, vol. 74, no. 4, pp. 714-719, 2006.

[21] B.-H. Chang, K. M. Skinner, and U. Boehmer, "Religion and mental health among women veterans with sexual assault experience," International Journal of Psychiatry in Medicine, vol. 31, no. 1, pp. 77-95, 2001.

[22] G. Burazeri, A. Goda, and J. D. Kark, "Religious observance and acute coronary syndrome in predominantly Muslim Albania: a population-based case-control study in Tirana," Annals of Epidemiology, vol. 18, no. 12, pp. 937-945, 2008.

[23] F. Gillum and C. Williams, "Associations between breast cancer risk factors and religiousness in American women in a national health survey," Journal of Religion and Health, vol. 48, no. 2, pp. 178-188, 2009.

[24] R. F. Gillum and D. D. Ingram, "Frequency of attendance at religious services, hypertension, and blood pressure: the third national health and nutrition examination survey," Psychosomatic Medicine, vol. 68, no. 3, pp. 382-385, 2006.

[25] D. H. Jaffe, Z. Eisenbach, Y. D. Neumark, and O. Manor, "Does living in a religiously affiliated neighborhood lower mortality?" Annals of Epidemiology, vol. 15, no. 10, pp. 804-810, 2005.

[26] T. Obisesan, I. Livingston, H. D. Trulear, and F. Gillum, "Frequency of attendance at religious services, cardiovascular disease, metabolic risk factors and dietary intake in Americans: an age-stratified exploratory analysis," International Journal of Psychiatry in Medicine, vol. 36, no. 4, pp. 435-448, 2006.

[27] W. R. Miller and C. E. Thoresen, "Spirituality, religion, and health: an emerging research field," The American Psychologist, vol. 58, no. 1, pp. 24-35, 2003.

[28] H. G. Koenig, D. E. King, and V. B. Carson, Handbook of Religion and Health, Oxford University Press, New York, NY, USA, 2nd edition, 2012.

[29] P. C. Hill, K. I. Pargament, R. W. Hood Jr. et al., "Conceptualizing religion and spirituality: points of commonality, points of departure," Journal for the Theory of Social Behaviour, vol. 30, no. 1 , pp. $50-77,2000$.

[30] H. G. Koenig, Spirituality and Health Research: Methods, Measurement, Statistics and Resources, Templeton Press, West Conshohocken, Pa, USA, 2011.

[31] D. E. Hall, K. G. Meador, and H. G. Koenig, "Measuring religiousness in health research: review and critique," Journal of Religion and Health, vol. 47, no. 2, pp. 134-163, 2008.

[32] J. S. Levin and H. Y. Vanderpool, "Is frequent religious attendance really conducive to better health?: toward an epidemiology of religion," Social Science and Medicine, vol. 24, no. 7, pp. 589-600, 1987.

[33] H. G. Koenig, J. C. Hays, D. B. Larson et al., "Does religious attendance prolong survival? a six-year follow-up study of 3,968 older adults," Journals of Gerontology B, vol. 54, no. 7, pp. M370M376, 1999.

[34] W. J. Strawbridge, R. D. Cohen, S. J. Shema, and G. A. Kaplan, "Frequent attendance at religious services and mortality over 28 years," The American Journal of Public Health, vol. 87, no. 6, pp. 957-961, 1997.

[35] T. D. Hill, A. M. Burdette, C. G. Ellison, and M. A. Musick, "Religious attendance and the health behaviors of Texas adults," Preventive Medicine, vol. 42, no. 4, pp. 309-312, 2006.

[36] W. J. Strawbridge, S. J. Shema, R. D. Cohen, and G. A. Kaplan, "Religious attendance increases survival by improving and 
maintaining Good health behaviors, mental health, and social relationships," Annals of Behavioral Medicine, vol. 23, no. 1, pp. 68-74, 2001.

[37] J. S. Levin, K. S. Markides, and L. A. Ray, "Religious attendance and psychological well-being in Mexican Americans: a panel analysis of three-generations data," Gerontologist, vol. 36, no. 4, pp. 454-463, 1996.

[38] P. C. Hill and K. I. Pargament, "Advances in the conceptualization and measurement of religion and spirituality: implications for physical and mental health research," The American Psychologist, vol. 58, no. 1, pp. 64-74, 2003.

[39] J. S. Levin, "Religion and health: is there an association, is it valid, and is it causal?" Social Science and Medicine, vol. 38, no. 11, pp. 1475-1482, 1994.

[40] Fetzer Institute, Multidimensional Measurement of Religiousness/Spirituality for Use in Health Research, Fetzer Institute, Kalamazoo, Mich, USA, 1999.

[41] B. Duffy, "Ipsos Global @dvisory: supreme Being(s)," the Afterlife and Evolution, 2011.

[42] C. G. Ellison and J. S. Levin, "The religion-health connection: evidence, theory, and future directions," Health Education and Behavior, vol. 25, no. 6, pp. 700-720, 1998.

[43] S. L. Blay, A. D. Batista, S. B. Andreoli, and F. L. Gastal, "The relationship between religiosity and tobacco, alcohol use, and depression in an elderly community population," The American Journal of Geriatric Psychiatry, vol. 16, no. 11, pp. 934-943, 2008.

[44] H. G. Koenig, L. K. George, H. J. Cohen, J. C. Hays, D. B. Larson, and D. G. Blazer, "The relationship between religious activities and cigarette smoking in older adults," Journals of Gerontology A, vol. 53, no. 6, pp. M426-M434, 1998.

[45] J. A. Patock-Peckham, G. T. Hutchinson, J. Cheong, and C. T. Nagoshi, "Effect of religion and religiosity on alcohol use in a college student sample," Drug and Alcohol Dependence, vol. 49, no. 2, pp. 81-88, 1998.

[46] L. Michalak, K. Trocki, and J. Bond, "Religion and alcohol in the U.S. National Alcohol Survey: how important is religion for abstention and drinking?" Drug and Alcohol Dependence, vol. 87, no. 2-3, pp. 268-280, 2007.

[47] K. J. Steinman, A. K. Ferketich, and T. Sahr, “The dose-response relationship of adolescent religious activity and substance use: variation across demographic groups," Health Education and Behavior, vol. 35, no. 1, pp. 22-43, 2008.

[48] L. Miller, M. Davies, and S. Greenwald, "Religiosity and substance use and abuse among adolescents in the national comorbidity survey," Journal of the American Academy of Child and Adolescent Psychiatry, vol. 39, no. 9, pp. 1190-1197, 2000.

[49] M. A. Whisman, K. C. Gordon, and Y. Chatav, "Predicting sexual infidelity in a population-based sample of married individuals," Journal of Family Psychology, vol. 21, no. 2, pp. 320324, 2007.

[50] S. S. Rostosky, M. D. Regnerus, and M. L. C. Wright, "Coital debut: the role of religiosity and sex attitudes in the add health survey," Journal of Sex Research, vol. 40, no. 4, pp. 358-367, 2003.

[51] M. Reindl Benjamins and C. Brown, "Religion and preventative health care utilization among the elderly," Social Science and Medicine, vol. 58, no. 1, pp. 109-118, 2004.

[52] M. R. Benjamins, "Religious influences on preventive health care use in a nationally representative sample of middle-age women," Journal of Behavioral Medicine, vol. 29, no. 1, pp. 1-16, 2006.
[53] J.-C. Suris, M. Nebot, and N. Parera, "Behaviour evaluation for risk-taking adolescents (BERTA): an easy to use and assess instrument to detect adolescent risky behaviours in a clinical setting," European Journal of Pediatrics, vol. 164, no. 6, pp. 371376, 2005.

[54] J. Sabaté, "Religion, diet and research," British Journal of Nutrition, vol. 92, no. 2, pp. 199-201, 2004.

[55] S. J. Rosen, Food for the Soul Vegetarianism and Yoga Traditions, Praeger, Santa Barbara, Calif, USA, 2011.

[56] J. White and E. White, Christian Temperance and Bible Hygiene, TEACH Services, Ringgold, Ga, USA, 2005.

[57] P. K. Mills, W. L. Beeson, R. L. Phillips, and G. E. Fraser, "Cancer incidence among California Seventh-day Adventists, 1976-1982," The American Journal of Clinical Nutrition, vol. 59, no. 5, pp. 1136S-1142S, 1994.

[58] J. E. Enstrom, "Cancer and total mortality among active Mormons," Cancer, vol. 42, no. 4, pp. 1943-1951, 1978.

[59] H. G. Koenig, M. E. McCullough, and D. B. Larson, Handbook of Religion and Health, Oxford University Press, USA, NY, USA, 2001.

[60] J. Groen and R. M. van der Heide, "Atheerosclerosis and coronary thrombosis," Medicine, vol. 38, no. 1, pp. 1-23, 1959.

[61] B. Shatenstein and P. Ghadirian, "Influence on diet, health behaviors and their outcome in select ethnocultural and religious groups," Nutrition, vol. 14, no. 2, pp. 223-230, 1998.

[62] K. O. Sarri, S. Higgins, and A. Kafatos, "Are religions "healthy"? A review on religious recommendations on diet and lifestyle," Human Ecology Special Issue, vol. 14, pp. 7-20, 2006.

[63] A. M. Coulston and C. J. Boushey, Nutrition in the Prevention and Treatment of Disease, Academic Press, 2008.

[64] L. Rew and Y. J. Wong, "A systematic review of associations among religiosity/spirituality and adolescent health attitudes and behaviors," Journal of Adolescent Health, vol. 38, no. 4, pp. 433-442, 2006.

[65] Y. J. Wong, L. Rew, and K. D. Slaikeu, "A systematic review of recent research on adolescent religiosity/spirituality and mental health," Issues in Mental Health Nursing, vol. 27, no. 2, pp. 161$183,2006$.

[66] C. H. Hackney and G. S. Sanders, "Religiosity and mental health: a meta-analysis of recent studies," Journal For the Scientific Study of Religion, vol. 42, pp. 43-55, 2003.

[67] J. Shannon, A. R. Kristal, S. J. Curry, and S. A. A. Beresford, "Application of a behavioral approach to measuring dietary change: the fat- and fiber-related diet behavior questionnaire," Cancer Epidemiology Biomarkers and Prevention, vol. 6, no. 5, pp. 355-361, 1997.

[68] F. E. Thompson and T. Byers, "Dietary assessment resource manual," Journal of Nutrition, vol. 124, no. 11, pp. 2245S-2317S, 1994.

[69] E. L. Idler, M. A. Musick, C. G. Ellison et al., "Measuring multiple dimensions of religion and spirituality for health research: conceptual background and findings from the 1998 general social survey," Research on Aging, vol. 25, no. 4, pp. 327$365,2003$.

[70] K. H. Kim, J. Sobal, and E. Wethington, "Religion and body weight," International Journal of Obesity, vol. 27, no. 4, pp. 469477, 2003.

[71] K. F. Ferraro, "Firm believers? Religion, body weight, and wellbeing," Review of Religious Research, vol. 39, no. 3, pp. 224-244, 1998. 
[72] H. Alexander, L. P. Lockwood, M. A. Harris, and C. L. Melby, "Risk factors for cardiovascular disease and diabetes in two groups of hispanic americans with differing dietary habits," Journal of the American College of Nutrition, vol. 18, no. 2, pp. 127-136, 1999.

[73] I. F. Hunt, N. J. Murphy, and C. Henderson, "Food and nutrient intake of Seventh-day Adventist women," The American Journal of Clinical Nutrition, vol. 48, no. 3, pp. 850-851, 1988.

[74] L. M. Kent and A. Worsley, "Does the prescriptive lifestyle of Seventh-day Adventists provide "immunity" from the secular effects of changes in BMI?" Public Health Nutrition, vol. 12, no. 4, pp. 472-480, 2009.

[75] R. J. Kuczmarski, J. J. B. Anderson, and G. G. Koch, “Correlates of blood pressure in Seventh-Day Adventist (SDA) and nonSDA adolescents," Journal of the American College of Nutrition, vol. 13, no. 2, pp. 165-173, 1994.

[76] I. L. Rouse, B. K. Armstrong, and L. J. Beilin, "The relationship of blood pressure to diet and lifestyle in two religious populations," Journal of Hypertension, vol. 1, no. 1, pp. 65-71, 1983.

[77] J. Sabate, K. D. Lindsted, R. D. Harris, and P. K. Johnston, "Anthropometric parameters of schoolchildren with different life-styles," The American Journal of Diseases of Children, vol. 144, no. 10, pp. 1159-1163, 1990.

[78] T. D. Shultz and J. E. Leklem, "Nutrient intake and hormonal status of premenopausal vegetarian Seventh-Day Adventists and premenopausal nonvegetarians," Nutrition and Cancer, vol. 4, no. 4, pp. 247-259, 1983.

[79] G. E. Fraser, W. Dysinger, C. Best, and R. Chan, "Ischemic heart disease risk factors in middle-aged Seventh-day Adventist men and their neighbors," The American Journal of Epidemiology, vol. 126, no. 4, pp. 638-646, 1987.

[80] F. H. Epstein, R. Simpson, and E. P. Boas, "Relations between diet and atherosclerosis among a working population of different ethnic origins," The American journal of clinical nutrition, vol. 4, no. 1, pp. 10-19, 1956.

[81] M. Glick, A. C. Michel, J. Dorn, M. Horwitz, T. Rosenthal, and M. Trevisan, "Dietary cardiovascular risk factors and serum cholesterol in an old order Mennonite community," The American Journal of Public Health, vol. 88, no. 8, pp. 1202-1205, 1998.

[82] T. Kita, M. Yokode, N. Kume et al., "The concentration of serum lipids in Zen monks and control males in Japan," Japanese Circulation Journal, vol. 52, no. 2, pp. 99-104, 1988.

[83] Y. Lee and M. Krawinkel, "Body composition and nutrient intake of Buddhist vegetarians," Asia Pacific Journal of Clinical Nutrition, vol. 18, no. 2, pp. 265-271, 2009.

[84] K. Mullen, R. Williams, and K. Hunt, "Irish descent, religion and food consuption in the west of Scotland," Appetite, vol. 34, no. 1, pp. 47-54, 2000.

[85] B. Shatenstein, P. Ghadirian, and J. Lambert, "Influence of the Jewish religion and Jewish dietary laws (Kashruth) on family food habits in an ultra-orthodox population in Montreal," Ecology of Food and Nutrition, vol. 31, no. 1-2, pp. 27-44, 1993.

[86] K. H.-C. Kim and J. Sobal, "Religion, social support, fat intake and physical activity," Public Health Nutrition, vol. 7, no. 6, pp. 773-781, 2004.

[87] K. H.-C. Kim, W. M. A. McIntosh, K. S. Kubena, and J. Sobal, "Religion,social support, food-related social support, diet, nutrition, and anthropometrics in older adults," Ecology of Food and Nutrition, vol. 47, no. 3, pp. 205-228, 2008.
[88] W. A. McIntosh and P. A. Shifflett, "Dietary behavior, dietary adequacy, and religious social support: an exploratory study," Review of Religious Research, vol. 26, pp. 158-175, 1984.

[89] D. G. Schlundt, M. D. Franklin, K. Patel et al., "Religious affiliation, health behaviors and outcomes: nashville REACH 2010," The American Journal of Health Behavior, vol. 32, no. 6, pp. 714-724, 2008.

[90] E. M. Arredondo, J. P. Elder, G. X. Ayala, N. R. Campbell, and B. Baquero, "Is church attendance associated with Latinas' health practices and self-reported health?" The American Journal of Health Behavior, vol. 29, no. 6, pp. 502-511, 2005.

[91] M. Baruth, S. Wilcox, and M. D. Condrasky, "Perceived environmental church support is associated with dietary practices among African-American adults," Journal of the American Dietetic Association, vol. 111, no. 6, pp. 889-893, 2011.

[92] M. R. Benjamins, "Religious beliefs, diet, and physical activity among Jewish adolescents," Journal For the Scientific Study of Religion, vol. 51, no. 3, pp. 588-597, 2012.

[93] K. Debnam, C. L. Holt, E. M. Clark, D. L. Roth, and P. Southward, "Relationship between religious social support and general social support with health behaviors in a national sample of African Americans," Journal of Behavioral Medicine, vol. 35, no. 2, pp. 179-189, 2012.

[94] K. J. Debnam, C. L. Holt, E. M. Clark et al., "Spiritual health locus of control and health behaviors in African Americans," The American Journal of Health Behavior, vol. 36, no. 3, pp. 360372, 2012.

[95] J. E. Fife, H. R. Sayles, A. A. Adegoke, J. McCoy, M. Stovall, and C. Verdant, "Religious typologies and health risk behaviors of African American college students," North American Journal of Psychology, vol. 13, no. 2, pp. 313-330, 2011.

[96] M. D. Franklin, D. G. Schlundt, L. H. McClellan et al., "Religious fatalism and its association with health behaviors and outcomes," The American Journal of Health Behavior, vol. 31, no. 6, pp. 563-572, 2007.

[97] Y. Friedlander, J. D. Kark, N. A. Kaufmann, and Y. Stein, "Coronary heart disease risk factors among religious groupings in a Jewish population sample in Jerusalem," The American Journal of Clinical Nutrition, vol. 42, no. 3, pp. 511-521, 1985.

[98] A. Hart Jr., L. F. Tinker, D. J. Bowen, J. Satia-Abouta, and D. McLerran, "Is religious orientation associated with fat and fruit/vegetable intake?" Journal of the American Dietetic Association, vol. 104, no. 8, pp. 1292-1296, 2004.

[99] A. Hart Jr., L. Tinker, D. J. Bowen, G. Longton, and S. A. A. Beresford, "Correlates of fat intake behaviors in participants in the eating for a healthy life study," Journal of the American Dietetic Association, vol. 106, no. 10, pp. 1605-1613, 2006.

[100] A. Hart Jr., D. J. Bowen, A. Kuniyuki, P. Hannon, and M. K. Campbell, "The relationship between the social environment within religious organizations and intake of fat versus fruits and vegetables," Health Education and Behavior, vol. 34, no. 3, pp. 503-516, 2007.

[101] C. L. Holt, D. L. Haire-Joshu, S. N. Lukwago, L. A. Lewellyn, and M. W. Kreuter, "The role of religiosity in dietary beliefs and behaviors among urban African American women," Cancer Control, vol. 12, pp. 84-90, 2005.

[102] L. A. Lytle, S. Varnell, D. M. Murray et al., "Predicting adolescents' intake of fruits and vegetables," Journal of Nutrition Education and Behavior, vol. 35, no. 4, pp. 170-178, 2003.

[103] T. Obisesan, I. Livingston, H. D. Trulear, and F. Gillum, "Frequency of attendance at religious services, cardiovascular 
disease, metabolic risk factors and dietary intake in Americans: an age-stratified exploratory analysis," International Journal of Psychiatry in Medicine, vol. 36, no. 4, pp. 435-448, 2006.

[104] C. L. Park, D. Edmondson, A. Hale-Smith, and T. O. Blank, "Religiousness/spirituality and health behaviors in younger adult cancer survivors: does faith promote a healthier lifestyle?" Journal of Behavioral Medicine, vol. 32, no. 6, pp. 582-591, 2009.

[105] L. Pitel, A. M. Geckova, P. Kolarcik, P. Halama, S. A. Reijneveld, and J. P. van Dijk, "Gender differences in the relationship between religiosity and health-related behaviour among adolescents," Journal of Epidemiology and Community Health, vol. 66, no. 12, pp. 1122-1128, 2012.

[106] R. R. Reeves, C. E. Adams, P. M. Dubbert, D. A. Hickson, and S. B. Wyatt, "Are religiosity and spirituality associated with obesity among African Americans in the Southeastern United States (the Jackson Heart Study)?" Journal of Religion and Health, vol. 51, no. 1, pp. 32-48, 2012.

[107] E. Salmoirago-Blotcher, G. Fitchett, J. K. Ockene et al., "Religion and healthy lifestyle behaviors among postmenopausal women: the women's health initiative," Journal of Behavioral Medicine, vol. 34, no. 5, pp. 360-371, 2011.

[108] A. Shmueli and D. Tamir, "Health behavior and religiosity among Israeli Jews," Israel Medical Association Journal, vol. 9, no. 10, pp. 703-707, 2007.

[109] S. M. Underwood and R. L. Powell, "Religion and spirituality: influence on health/risk behavior and cancer screening behavior of African Americans," The ABNF Journal, vol. 17, no. 1, pp. 20-31, 2006.

[110] W. H. Wiist, B. M. Sullivan, D. M. St. George, and H. A. Wayment, "Buddhists' religious and health practices," Journal of Religion and Health, vol. 51, no. 1, pp. 132-147, 2012. 


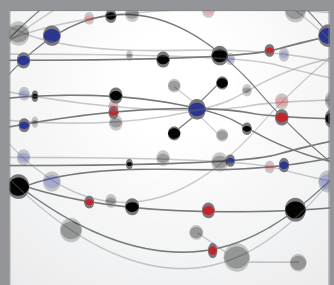

The Scientific World Journal
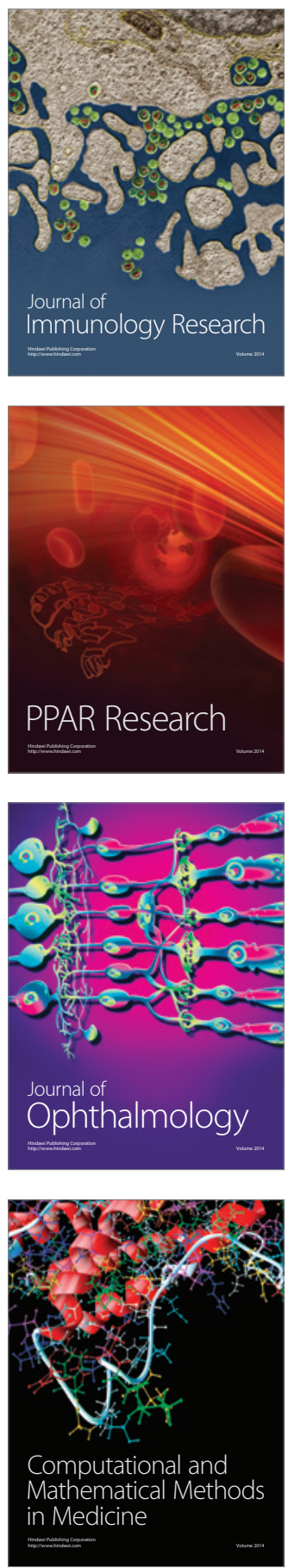

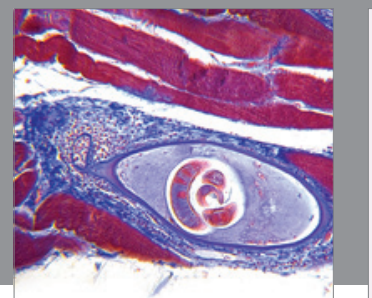

Gastroenterology

Research and Practice
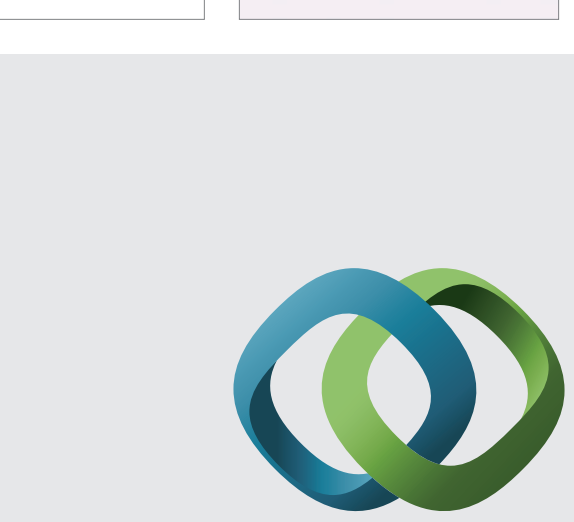

\section{Hindawi}

Submit your manuscripts at

http://www.hindawi.com
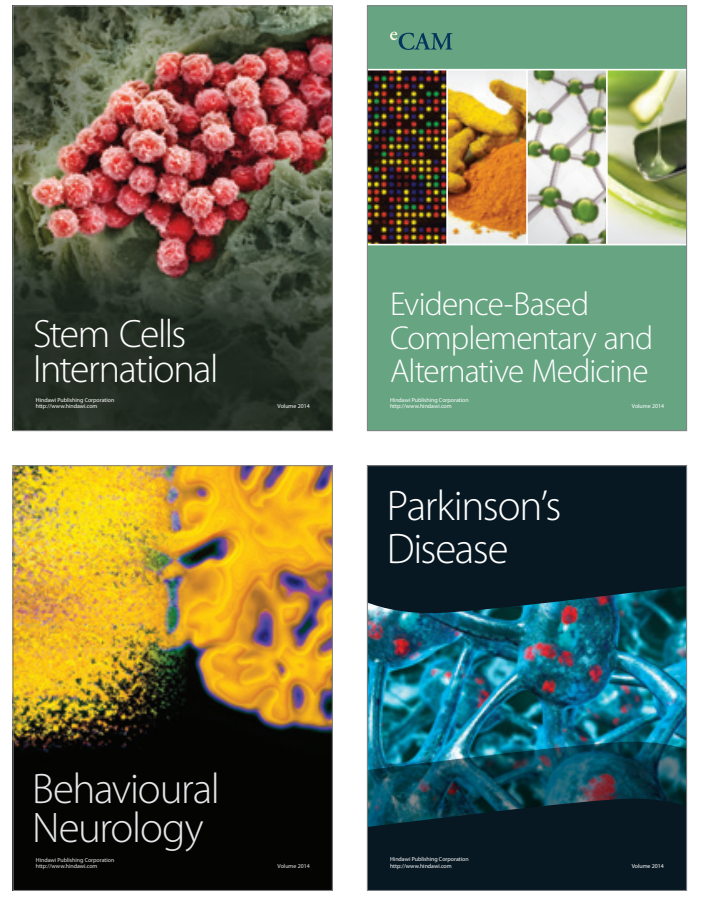
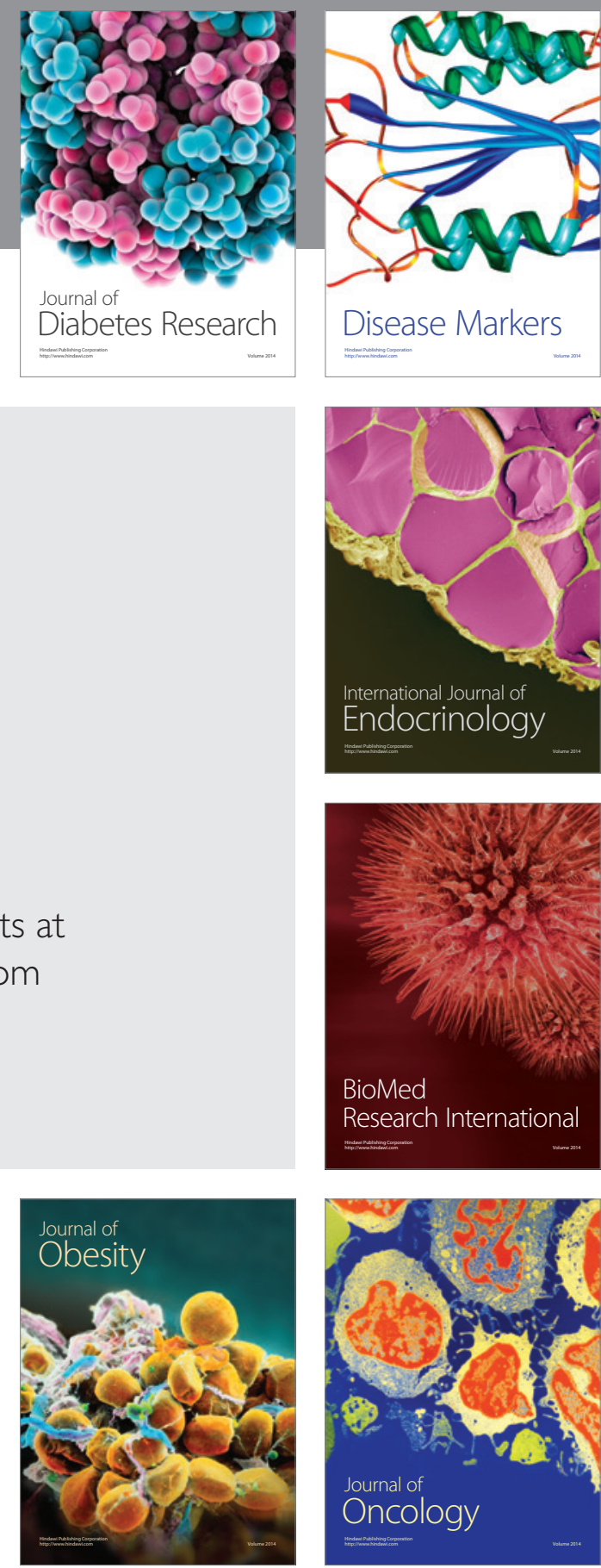

Disease Markers
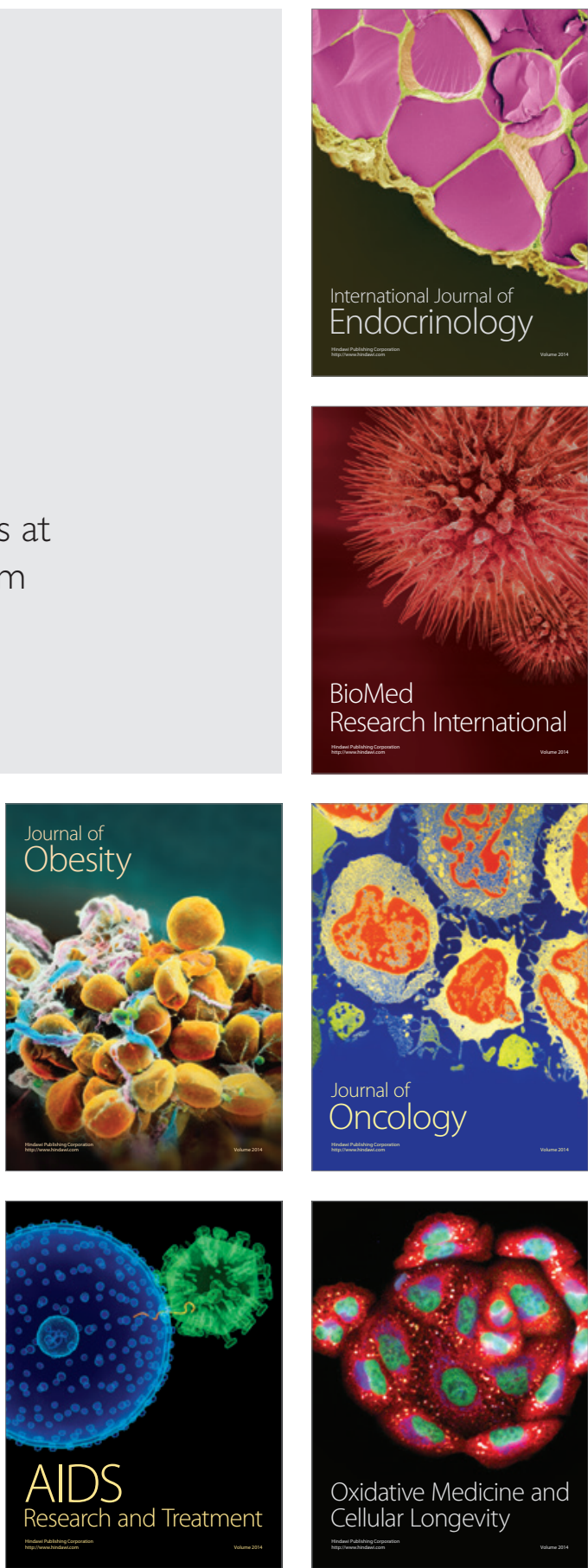